\title{
Teachers as Researchers: A discovery of Their Emerging Role and Impact Through a School-University Collaborative Research
}

\author{
Ken Chi Kin Chow \\ Samuel Kai Wah Chu \\ Nicole Tavares \\ Celina Wing Yi Lee \\ Faculty of Education \\ The University of Hong Kong
}

\begin{abstract}
This study explored the impact of the role of teacher-researchers on in-service teachers' professional development, as well as the reasons behind the lack of a teacher-as-researcher ethos in schools. In the study, teachers from four Hong Kong primary schools participated in a school-university collaborative research project that promotes collaborative inquiry projectbased learning (inquiry PjBL). During the project implementation period, the teachers took the dual role of the teacher and researcher. Six focus group interviews were conducted with the teachers to collect in-depth qualitative data on their experiences. The impact of this experience on teacher professionalism was examined from four dimensions: knowledge enrichment, school culture, teaching practice and curriculum design. The study provides evidence for the benefits of teacher research and sheds light on how university-school collaboration could contribute to engaging teachers in action research in their everyday classroom.
\end{abstract}

Keywords: Teacher research, school-university collaboration, inquiry project based learning

Dr Chow is the Principal of Sacred Heart Canossian School and the former Principal of Canossa Primary School. Besides his engagement as a school leader and administrator, he serves and holds currently various positions at the Education Bureau of Hong Kong where he gives advice on the development of learning and teaching for the local community. Email: ckchowa@graduate.hku.hk

Dr Chu is the Head and an Associate Professor (Division of Information and Technology Studies) and Deputy Director (Centre for Information Technology in Education) in the Faculty of Education, The University of Hong Kong. He has published over 200 articles and books including key journals in the area of game-based learning and gamification, information and library science. Email: samchu@hku.hk

Ms Tavares is a Senior Lecturer in the Faculty of Education, HKU. Her expertise ranges from ELT methodology, collaboration and inquiry learning to uses of information technology on teacher professionalism. She was recipient of her Faculty's Distinguished Teacher Award (2006), Knowledge Exchange (Team) Award (2010) and Teacher Effectiveness Award (2015). Email: tavaresn@ hku.hk

Ms. Lee holds a Bachelor Degree in English and Spanish, and Postgraduate Diploma of Education in English, Secondary School. She has been involved in conducting research in the field of IT in Education, inquiry learning and development of 21st century skills with Dr Chu. Email: celinalee510@gmail.com 


\section{Introduction}

In recent years, the Education Bureau (EDB) of the Hong Kong Special Administrative Region (HKSAR) has incorporated project-based learning (PjBL) into its General Studies (GS) curriculum in primary schools. The prime goals of PjBL are to facilitate students' development of basic knowledge, investigation skills and problem-solving capabilities (EDB, 2002). To explore the significance of this relatively new initiative, a school-university collaborative research project was carried out from 2009 to 2011 in four primary schools in Hong Kong. The project aims to promote collaborative inquiry project-based learning as well as to explore how teaching strategies can be adjusted to fit the implementation of inquiry PjBL. Teachers from four different subject areas, including: 1) Chinese Language, 2) General Studies, 3) Information Technology, and 4) Teacher Librarians, had worked together as a team to equip their students with the knowledge and skills needed for inquiry PjBL. This research project conducted by The University of Hong Kong presented the teachers with the opportunity to reflect on their own teaching practice through collecting empirical evidence from their own classroom. Participating teachers were engaged in conducting research through working with their colleagues at both intra- and inter-school levels and with university experts. Focus group interviews were conducted with participating teachers to investigate the impact of the role of researcher on teachers' sense of professionalism and the driving force and constraints that influence the establishment of a research culture in schools.

A closer look at the various factors affecting teachers' engagement with classroom-based research is believed to shed light on the implications for their continued professional development in schools. Furthermore, a study on collaborative modes between university and school, and among frontline teachers both within and across schools, is expected to provide government officials and school leaders with insights into effective ways of implementing curriculum changes and reforms in real-life situations in the Hong Kong classroom. This paper discusses the possible reasons for the lack of a teacher-as-researcher ethos, and the push-and-pull factors that affect teachers' willingness in taking up a researcher role.

\section{Literature Review}

The following literature review will focus on three major aspects of this research topic: (1) teacher professionalism, (2) teacher research in general and (3) the challenges of implementing teacher research in Hong Kong.

\section{Teacher Professionalism}

The term "teacher professionalism" appears very often in literature, but there has been little consensus on its definition. Scholars attach different meanings to teacher professionalism. For example, Hoyle (1980) describes professionalism as the quality of practice, which refers to (1) the manner of conduct within an occupation, (2) the integration of obligations with knowledge and skill among members of the profession, and (3) the contractual and ethical relations with clients. According to Tschannen-Moran (2009), teacher professionalism refers to teachers' perceptions that their colleagues take their work seriously, demonstrate a high level of commitment, and go beyond minimum expectations to meet the needs of students. Morrow and Goetz (1988) included 13 areas in their Likert-type questionnaire designed to measure teacher 
professionalism: (1) independent practice, (2) code of ethics, (3) licensing, (4) single major professional association, (5) exclusive practice rights, (6) body of specialized knowledge, (7) application of knowledge in professional practice, (8) collaboration among members, (9) candidate selection, (10) rigorous and protracted study/training period, (11) high status, (12) high compensation, and (13) life-long commitment. In spite of the diverse interpretations of teacher professionalism, it is evident that some areas are given greater prominence in the definition of teacher professionalism, such as the use of professional knowledge in practice and commitment to the profession.

Teacher professionalism is well established in the literature as an important determinant in the pursuit of educational excellence (Toh, Diong, Boo \& Chia, 1996). In an attempt to deepen his understanding of professionalization and bureaucratization, Hall (1968, as cited in Toh, et al., 1996) identified five attributes that are regarded as most relevant to teacher professionalism: (1) use of the professional organization as a major referent, (2) belief in service to the public, (3) belief in self-regulation, (4) a sense of calling to the field, and (5) autonomy for decision making. Biggs (1994) suggested that teachers enhance their professionalism when they make active attempts to link and apply educational theories to their practice. Sellars (2012) highlighted deep reflection on teaching practice and education issues as an essential attribute in teachers' capacity. Frost, MacBeath, O'Donovan, Sapsed, \& Swaffield, (2013) asserted that environments which sustain teacher professional growth are characterized by teachers engaging themselves in a theory-building process. As there is a lack of agreement on what contributes to teacher professionalism, this study aims to examine how engagement in action research fosters teachers' sense of professionalism. In particular, we look into professionalism in four aspects: (1) knowledge enrichment, (2) ability to reflect upon and improve one's own teaching practice, (3) strengthened confidence in one's ability to initiate changes in school culture, and (4) school curriculum design.

\section{Teacher Research}

Many labels have been used for the kinds of research that are conducted by teachers in the classroom and at school, such as:

(1) 'action research' (Elliott, 1991; Zeichner, 1993);

(2) 'practitioner research' (Zeichner \& Noffke, 2001);

(3) 'collaborative inquiry' (Bray, 2000);

(4) 'critical inquiry' (Aaron, et al., 2006);

(5) 'self-study' (Bullough \& Pinnegar, 2001), and

(6) 'teacher-research' (Cochran-Smith \& Lytle, 1993, Cochran-Smith \& Lytle, 1999; MacLean \& Mohr, 1999).

Putting aside these different labels, teacher research is a process in which educators note 'problems' in the context of their own schools and classrooms and propose investigative methods appropriate to address the problems. Educators also systematically observe and analyze the results in the light of their professional knowledge, and share the results with others, while enacting change in their own classrooms (Bissex \& Bullock, 1987; Cochran-Smith \& Lytle, 1999; Goswami \& Stillman, 1987; Kincheloe, 2003; Loughran, 2002; MacLean \& Mohr, 1999; Myers, 1985). Teacher-research commonly makes use of qualitative data, including journals, oral 
inquiries and observational data (Cochran-Smith \& Lytle, 1993) and is often reported in narrative forms of representation. As a powerful and applicable tool to examine and evaluate an issue or phenomenon in a systematic and rigorous way, school-based research carried out by teachers is believed to be an explicit and practical way of creating educational knowledge (Hargreaves, 1998).

Learning to teach is a lifelong process, so it is essential to provide ongoing and meaningful opportunities for professional development for in-service teachers to foster advancement in their pedagogical expertise (Atay, 2008). Teacher research has been proposed as a means to facilitate this professional growth of both pre- and in-service teachers, while promoting critical reflection, change and reform in K-12 settings (Roulston, Legette, Deloach, \& Pitman, 2005; Rust, 2009; Rathgen, 2006).

Clausen, Aquino \& Wideman (2009) cited an example of a learning community model which requires teachers to carry out research projects and reflect on their own practice during and after the projects, aside just acquiring knowledge from university experts outside school.

The authors believed that such a model could enable the teachers to become active in the learning process. Furthermore, teachers in a learning community are no longer seen as receivers of "ideal" knowledge, but they learn and construct, through real-life experiences, their pedagogical knowledge with the support of experts. Watkins' (2006) interviews with practicing teacher-researchers, revealed that research was a vehicle for their professional learning. Through the ongoing and reflective nature of this type of research, in-service teachers acquire the skills of problematizing their seemingly good practices and ask questions about their daily teaching routine. Such reflection is important in developing plans of actions to find answers to the questions, make careful observations, draw conclusions from the evidence they gather, and use what is learned to facilitate changes in their own pedagogy (Shakir-Costa \& Haddad, 2009).

Teacher research has also been shown to have positive effects on the professional competence of teachers since action research is a necessary and integral part of the process of developing teaching as an evidence-based profession (Furlong \& Salisbury, 2005). Fullan (2013) found that one of the critical factors for more frequent innovative education is that teachers engaged in "professional development activities that involve the active and direct engagement of teachers, such as teachers conducting research or directly practicing new methods" (p. 43). Teachers' ability and interest taking the role in leading first-hand research would be significant to bringing about innovative teaching and facilitating their professional development.

\section{Teacher Research in Hong Kong: Challenges}

For teacher research to take place in Hong Kong, a lot of consideration and work have to be taken into account to overcome the existing challenges. First, teachers in Hong Kong lack training in research skills. To be qualified as a registered teacher in Hong Kong, one is required to possess the approved teacher qualifications specified in the Education Ordinance (EDB, 2008). Most of the qualified teacher training programs, such as Postgraduate Diploma in Education (PGDE) program, equip pre- and in-service teachers with a variety of skills ranging from subject-specific knowledge in lesson and curriculum design to knowledge in education policies and moral education. However, research skills are very often not given much emphasis in the teachers' training, and their ability to conduct classroom-based research is seldom a core component used to evaluate their performance. 
Time constraint is another impeding factor. Apart from teaching and marking students' work, teachers who hold administrative positions such as coordinators of teams at school take charge of extra-curricular activities. They also join professional development programs to keep themselves abreast with the latest pedagogical and methodological developments amid the challenges brought about by the local education reforms. According to a survey, most teachers reported shouldering heavy administrative responsibilities requiring them to attend meetings, do clerical work, prepare proposals and reports, organize promotional activities for student recruitment purposes, and others (HKIED, 2010). The results of the survey have also indicated that a teacher worked an average of 9.8 hours on school days and spent about the same amount of time during weekends on school work. It is natural to say that with their preoccupation with these daily tasks, teachers can rarely spare time for research. The examination-led education system in Hong Kong is often said to be an explanation for teachers' non-engagement in research. This focus on examinations puts enormous stress not only on students but also on teachers. As the results of the students' performances in these examinations will affect their chances of further study as well as the banding of their respective schools, teachers admit experiencing pressure during the process of equipping their students with the knowledge and skills to perform well in the examinations (DAB, 2002). The exam-oriented education is perhaps a prime reason why there seem to be few teacher-researchers in Hong Kong.

Cultural factors also hinder the flourishing of teacher research. Traditionally, teachers have not been required as part of their duties to conduct research. In Hong Kong, there is a clear distinction between the role of the teacher as a practitioner and that of a researcher. Berger, Boles and Troen's (2005) study found that teachers were unfamiliar with or even intimidated by the concept of research. Some teachers were resentful of the idea of conducting teacher research as they regarded it as something "complex" and "sophisticated" such that only academics at universities could do (Campbell, 2003). Watkin's (2006) findings concluded from his interview with teachers that research is not something every teacher is keen on engaging themselves in. This view of educational research is very prevalent among teachers in Hong Kong, who tend to believe that research is solely done by university scholars, and they have a minimal role to play in it.

Even for teachers who are ready to take on a researcher role, channels or platforms for them to publish the findings of their study are found to be lacking. Hong Kong Education City Limited (HKEdCity) serves as a platform to bring teachers into the territory together. However, it is more often seen as a resource-sharing site instead of an official and authoritative avenue for the dissemination of research findings that are geared towards knowledge-sharing. Academic journals tend to have high standards for articles to be published, thereby deterring teachers from submitting their research findings for publication. There is a need for a school-teacher-based magazine, journal or network for teachers to fill this knowledge gap.

\section{Research Design}

In the light of the above, the present study explores and aims to address the following questions:

1. What is the impact of the school-university collaborative research project on teachers' teaching practices and their professionalism?

2. Is school-university collaboration a feasible alternative to overcome the obstacles faced by teachers in conducting teacher research? 
3. What are the other factors that can help foster a research climate in schools in Hong Kong?

Thirty-two teachers from four primary schools in Hong Kong took part in the schooluniversity collaborative research project. They included twelve Chinese Language teachers, twelve General Studies (GS) teachers, eight Information Technology (IT) teachers and four teacher librarians. Eight of the teachers were male, and twenty-four of them were female. Eight teachers took the role of teacher coordinators (TCs), responsible for meeting with the investigators from the university and guiding their colleagues at school in conducting the research project. TCs, occasionally accompanied by their colleagues, had regular meetings with the university investigators to reflect on various aspects of the research process and contributed to the refinement of their research design. In the monthly administrative meetings, teachers discussed with the investigators the ways in which the project can be carried out in their classroom setting more effectively. Specifically, the teachers were involved in developing, examining and refining the instruments used in the project, such as questionnaires. They also played a part in the data analysis and interpretation process. Some of these teachers were eventually the first author or co-author in several publications about the project, including six conference papers and five seminar papers. The publication list can be found in Appendix 1.

This project suggested that the ideal collaboration between university and schools is one in which teachers work closely with university experts in discovering new knowledge instead of relying on them. The difference between collaboration with and reliance on university experts is clearly depicted in the following figures:

Figure 1. Two Modes of Interaction between University Experts and Frontline Teachers.

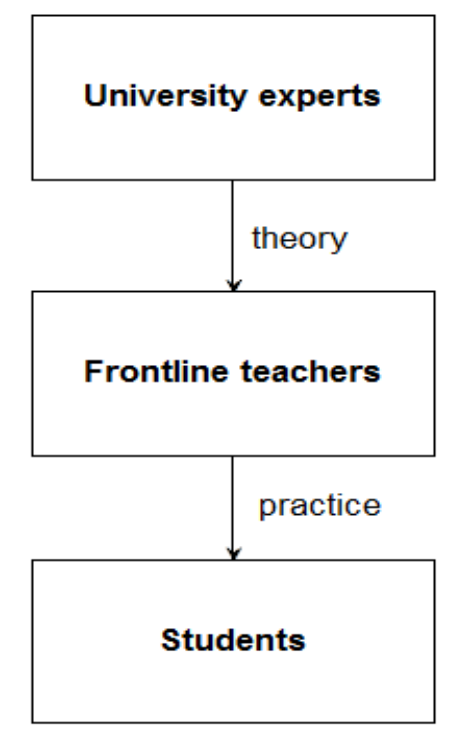

Reliance on university experts

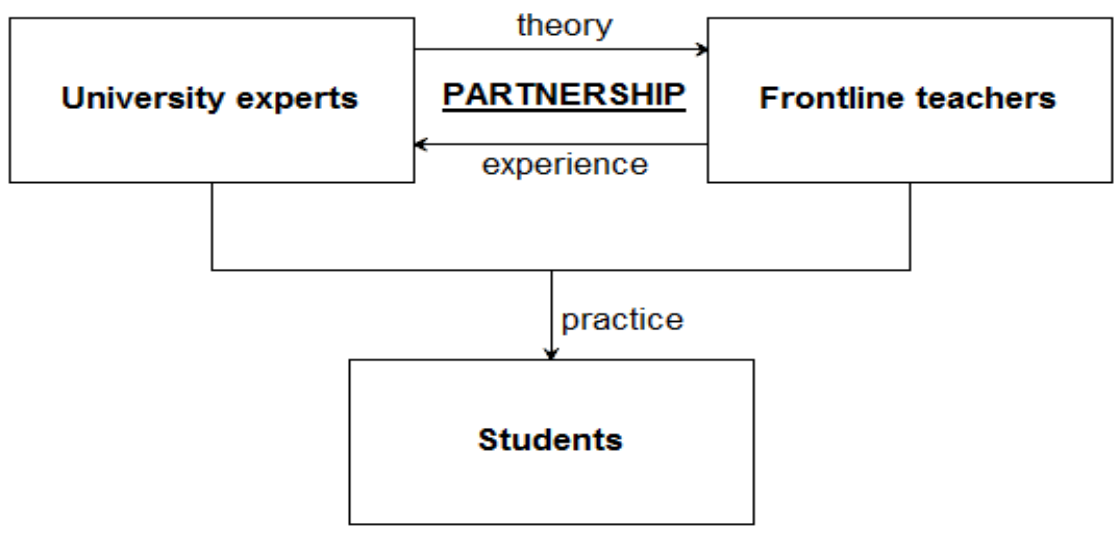

Collaboration with university experts

In the first situation (Figure 1 left), the frontline teachers count on the experts to provide them with theoretical knowledge to facilitate their students' learning. Their roles are thus passive recipients in the research process. In scenario 2 (Figure 1 right), the frontline teachers are 
partnering with the university experts in generating knowledge and theorizing their practice, through which students benefit from the renewed/revised practice. This collaborative model of school-university partnership should be advocated. In addition, it is hoped that teachers will take the next step in becoming teacher-researchers rather than merely relying on university experts, just being a part of their research agenda and/or serving as a simple bridge between the experts and the students.

This overall study looked at the impact of the teacher-researcher role taken by the participating teachers on their professionalism and professional development. Five focus group interviews were conducted with the thirty-two participating teachers to collect qualitative data on their experiences, comments and reflections on their role as teacher-researchers in the schooluniversity collaborative research project. One additional focus group interview was done with the TCs. Each focus group interview lasted fourty-five to sixty minutes, with each group comprising five to ten teachers. An interview protocol with nine guiding questions was prepared. Questions tapped into teachers' understanding of their professional development along with the research implementation, such as: "What have you learned, in terms of teaching, from this research project?" "Generally speaking, since joining the research project, how would you describe the link between the project and your everyday teaching practice?" "Has your participation in the project changed your perception of teacher professionalism? If so, in what way?" Despite the nine guiding questions, the interviewer was not required to ask all of them in an interview. The interviewer would end the interview only when all teachers felt that they had enough time to share their experience in the project. All the interviews were audio taped and transcribed by research assistants. The data were primarily coded by a research assistant. A coding criterion was generated and a proportion of $20 \%$ of the data was coded by another research assistant in order to check the reliability of the coding scheme. The inter-rater agreement was over $90 \%$. The section below will report on the findings of the study. All names mentioned in the section are pseudonyms to protect the privacy of the participants.

\section{Findings}

\section{(1) What is the Impact of the School-University Collaborative Research Project on Teachers' Teaching Practices and Their Professionalism?}

The impact of the school-university collaborative research project on the participating teachers' teaching in their everyday classroom and their professionalism was examined. From the focus group interviews, teachers, in general, reported that their engagement in the research project had a positive influence on their professionalism. In particular, they found significant influence in four leading aspects, namely knowledge enrichment, school culture, teaching practice and curriculum design.

\section{Knowledge enrichment}

The participating teachers indicated their overall perception that their knowledge of and skills in using different teaching methodologies have been boosted in the process of carrying out the research project with input from workshops facilitated by university experts. These teachers also felt they have gained more methodological knowledge and skills through taking part in experience-sharing sessions with colleagues at school and with other teacher participants, as part 
of the research project. A Chinese Language teacher, Claudia, acknowledged her advancement in IT and information literacy throughout the research period, with the assistance of the university experts. She reported, "My IT knowledge used to be basic. Before participating in the project, I often resorted to using Yahoo or Google. Now, at least I know what WiseNews ${ }^{1}$ is when my students ask me about it."

Several teachers reported learning new IT skills, such as Web 2.0 technologies, especially in the use of PBworks - a Wiki technology that provides space for people to work collaboratively on a project online. GS teacher Christie expressed having greater confidence in using Web 2.0 technologies that she can now share with her students, "With Web 2.0 tools, students learn how to engage themselves in group discussions beyond the classroom. Their interactions are now of a higher quality, and I believe this is a good way to create an opportunity for them to help one another."

In addition to the improvement in IT and information literacy skills, teachers perceived sharpened knowledge of how to bring inquiry-based projects into their classrooms. Another Chinese Language teacher Louise, a TC, exclaimed, "I have gradually deepened my understanding of how to implement inquiry project-based approach. I now experience a great sense of satisfaction when guiding my students through a project like this."

The school-university collaborative research project seems to have offered the participating teachers an opportunity to learn from university experts and other teacher practitioners through regular meetings to discuss their research projects.

\section{School culture}

The school-university collaborative research project also played a role in heightening the teachers' sensitivity to the importance of cross-disciplinary collaboration and sharing as part of their professional development. Through sharing their experiences and reflections with colleagues within and outside the school, teachers came to realize that stronger cooperation and closer communication with colleagues all add up to contribute to the development of more effective teaching strategies. In the words of Chinese Language teacher Claudia:

We learn to work hand in hand with teachers of different subjects to ensure that the teaching plans and schedules all cohere to prepare our students well for their inquiry-based project. More importantly, given time constraints, we had to make every effort to avoid repetition in the teaching of similar skills.

Collaboration among teachers did not only happen in schools. Because TCs attended meetings with the university experts on a regular basis, exchange of knowledge also took place among teachers from different participating schools. According to TC Louise, "It is not common for teachers in Hong Kong to share their teaching experiences with colleagues, be it within or outside schools. But this project made it happen."

\footnotetext{
${ }^{1}$ Wisenews is the largest Chinese database of published information including all 18 Chinese and English newspapers in Hong Kong and other top tier newspapers, magazines, newswires, TV and radio channels in Greater China.

(http://www.wisers.com/corpsite/global/en/products/wisesearch.html)
} 


\section{Improvement in teaching strategies}

Because of their active involvement in the project, the teachers were in an environment that engaged them in ongoing reflection on their original way of teaching and their daily experiences, with guidance provided by university experts. As GS teacher, Winnie stressed in an interview:

I used to study in a school that favored rote memorization and where the interaction between teachers and students has operated in a unitary direction. Now, I learn to teach using an inquiry-based approach and through collaborating with my fellow colleagues and university people.

Carol, a Chinese Language teacher from the same school as Winnie, highlighted her discovery:

At the very beginning, we had a very shallow understanding of what projectbased learning is. I thought that this approach is common practice in most schools in Hong Kong. We teachers focused too much on the final output, so we spent a great deal of time helping our students complete their work to perfection because we felt they did not have the ability to do so. With the guidance of and input from the university experts in our teaching and planning process, we began to discover what it means to be truly facilitating our students' learning when doing an inquiry project. We understood that it was much more crucial to focus on their learning process rather than simply on the end product.

\section{Ability to improve school-based curriculum design}

The teachers' active participation in refining and implementing the research project was found to have led to profound changes in the curriculum design of various subjects at their schools. IT teacher Kitty described her experience:

We have revised our syllabus at school to teach students the skills in using PowerPoint and Excel in Primary 4 instead of Primary 5. We hope to give them the knowledge they need to make graphs and charts for their presentations based on their inquiry-based projects.

Teacher librarian Tina also noticed curriculum changes in Library Studies at her school. She said, "The teaching of skills to help students with their information search to gather what they need online from different electronic databases has become a new topic for us."

Another teacher Chloe modified her school-based Chinese Language curriculum by giving her students more focused input on how to summarize and organize information. She also made every effort to ensure that what her students were learning in Chinese was in line with the teaching schedule of the GS curriculum:

Now that we are adopting inquiry-based learning in our teaching, we work closely with the GS teachers to guide students in completing their GS project. In 
the project, we felt that summarization and critical thinking skills are needed, so we introduced them sooner in our curricula.

Engaging in the school-university collaborative research project helped the teachers to reflect on the pedagogical practices they had long been adhering to and to be exposed to new ideas. Felix, one of the TCs, also held the view that after trying out a collaborative teaching approach in his school, frontline teachers felt more empowered to review the curriculum critically at his school:

Because we had to work with the GS teachers in preparing our students for the GS project, we taught PowerPoint earlier in our teaching schedule. In the past, we felt very much confined to following the teaching guidelines and taught PowerPoint in Primary 4. Now we are convinced that even Primary three students have the ability to handle the skills of using PowerPoint. So we have exercised our professional discretion to move the teaching of this IT skill to the lower primary curriculum.

There is therefore ample evidence to illustrate the growth in the participating teachers' pedagogical knowledge and professionalism to cope with the need for school-based curriculum changes to address their students' needs.

\section{(2) Is School-University Collaboration a Feasible Alternative to Overcome the Obstacles Faced by Teachers in Conducting Teacher Research?}

From the literature on what hinders teachers from classroom-based research and from what has been previously discussed in response to the first research question, school-university collaboration appears to be a possible solution to some of the deterrents. University scholars have the relevant expertise, knowledge and skills to support teacher-researchers both intellectually and technically in carrying out research studies in their classrooms. Participating teachers in this school-university collaborative research project have provided further testimony to this. When asked what was of greatest significance to her in the project, Chinese Language teacher Claudia remarked:

I have learned more IT and information literacy skills from the training workshops organized by experts at the university. For example, I am now aware that electronic databases can be a useful resource to gather information, and eplatforms can be a valuable avenue for students to have discussions online.

Apart from hands-on training and new learning at the workshops, GS teacher Winnie suggested,

University experts may help prepare some practical materials such as teaching plans and guidelines to support teachers in their daily teaching and hence boost their confidence in experimenting with this new teaching approach.

In addition to substantial knowledge input, this school-university collaboration has proven itself to have a positive impact on the school culture as TC Felix admitted: 
School-university collaboration in conducting research helps promote and gradually shape the school culture as teachers who took part in the project become more open-minded and innovative, and are empowered with the courage to at least take the initiative to explore and attempt new teaching practices.

Nevertheless, it has been observed that although some teachers realize that they can take greater initiatives in the research process, they do not see the value of further becoming teacherresearchers to advance their teacher professionalism and contribute to educational research. In the next section, the push-and-pull factors of fostering a research culture among teachers will be highlighted.

\section{(3) What are the Other Factors that can Help Foster a Research Climate in Schools in Hong Kong?}

Internal and external forms of support, collaboration among school principals, colleagues from both within and beyond the same teaching context, as well as with students and their parents are considered to be critical factors in the cultivation of a teacher-as-researcher culture.

\section{Administrative support from school}

School principals are deemed to play an integral part in the establishment of a school culture that encourages teachers to carry out research in their classrooms. As TC Tiffany opines,

Support from school administrators is essential to the implementation and success of research projects like this one. The principal in our school played a hugely influential part in urging all teachers to be involved.

Moreover, the opportunity to share research outcomes at least with colleagues at school, if not across schools, is initially a kind of recognition of the time and effort teacher-researchers have invested in their work. This kind of intra- and inter-school sharing and knowledge exchange is believed to not only stimulate teachers to reflect upon their own teaching practices, but also act as an impetus for other teachers to see the potential benefits of engaging in classroom-based research. Implicit and explicit support for and close communication with colleagues is said to be a complementary force that is conducive to an environment that promotes research in the classroom. It is also imperative for the Academic Coordinator at school to oversee the timetables and teaching schedules of different subjects among various classes to create a common block for mutual exchange to facilitate the research process.

\section{Parental support}

Aside from collaboration among the teaching staff, parents' attitudes towards and support for research are vital since their consent must be obtained before any form of classroom intervention could take place. According to a teacher participant Lily,

Parents are very much concerned about their children's examination results and exert pressure on teachers to spend more time on textbook materials. 
This challenges teacher-researchers to strategically strike the right balance between the time and effort put into teaching and conducting research or integrating the two to ensure that their students' academic results are not sacrificed at the expense of research.

\section{Changing the examination-oriented education system}

As mentioned in the earlier discussion, examinations in Hong Kong have been recognized as a significant burden not only on students but also on teachers, taking away their time for classroom-based research and hence improvement of their teaching. There needs to be more indepth and critical reflection on the part of the education sector and the government. The current education system needs to be reviewed for a new assessment framework with less stress laid on examinations and more on formative school-based assessments. The examination pressure on both students and teachers has to be relieved to create more room for teachers to engage themselves in classroom-based research which improves the overall teaching and learning experience. Only through such an overhaul could more teachers have the chance to experience being teacher-researchers and enjoy the benefits of classroom-based research.

\section{Establishing a knowledge-sharing community}

Last but not least, the sharing of teaching experiences among teachers across schools is yet to be a norm in Hong Kong. The university can be a vehicle that fosters inter-school sharing and exchange of knowledge and experience through seminars in which existing teacher-researchers from different schools share their first-hand experience and what they have learned from the process. An international survey (Mourshed, Chijioke \& Barber, 2010) revealed that those school systems in the category of "from Great to Excellent" emphasize learning through peers and innovation. Their interventions at different levels of systems reflected that collaboration amongst educators and decentralized pedagogical rights to schools and teachers are among some practical ways to raising the caliber of teachers and principals. Further, the report indicated that the experience of sharing innovation from the frontline across schools was another factor that supported and encouraged teacher professional development and thus facilitated school innovations. This may be one of the ways to recognize the efforts of teacher-researchers and possibly serve as a channel to attract other teachers to join the teacher-researcher community.

\section{Discussion}

\section{School Cultures for Fostering Teacher Research}

Besides the benefits, such as knowledge enrichment, as derived from participating in this schooluniversity collaborative project, the findings reveal that participating teachers also began their inquiry of teaching practice. With proper assistance and guidance from university academics, teachers started writing research reports (see Appendix 1) and presented their ability in analyzing their research outcomes. It needs to be noted, however that conducting teacher research can be quite difficult for some teachers. There is also a potential tension between research and other pressures being placed upon schools. For instance, the Hong Kong government has set many agendas for schools but doing research is rarely a priority for teachers (Watkins, 2006). Christenson, et al., (2002) reported that the lack of sharing culture among teachers is another 
common obstacle to teachers' involvement in research. The findings of this study; however, indicated that inter- as well as intra-school teacher sharing were supportive factors for fostering collaborative inquiry in teaching. Thus, the knowledge-sharing community is found to be a crucial platform for sustaining the environment for teacher research. On the other hand, some school principals and colleagues may not be supportive enough or may even be hostile towards teacher research. Both internal and external support and collaboration among colleagues, senior management as well as higher institutions such as universities are crucial motivators for teachers to conduct classroom-based research. These parties not only provide expertise and guidance but also contribute to the research culture in schools (Watkins, 2006).

Additionally, the structure of schools, such as the school culture and the management style of the school, can affect the outcome of teacher research. A school's culture seriously influences how teachers perceive and respond to teacher research (McDonald and Elias, 1983; Christenson et al., 2002; Mohammad \& Harlech-Jones, 2008). MacGilchrist, Reed and Myers (2004) observed that the culture of a school is manifested in its daily life through the professional relationships among the teachers at school and other members of staff working with one another and their pupils and the school management (as cited in MacGilchrist, Mortimore, Savage, Beresford, 1995). In this study, it was found that teachers perceived support from administrators, and positive collaboration relationship among peers, as essential elements which contribute to an environment that promotes teacher research. School principals play a significant role in establishing the norms and structures that allow schools to develop and operate as professional learning communities (Louis and Kruse, 1995; Louis, Marks \& Kruse, 1996). On one hand, the role of school administrators and their direct support are imperative for teacher research. Supportive and sympathetic school principals are essential for providing the necessary time and resources for teachers to conduct classroom-based research, through a reduction in teachers' normal teaching duties, for instance (Croasdaile, 2007).

Teachers immersed in school cultures that are supportive of and positive towards teacher research are expected to be more involved in classroom-based research. Apart from administrative support, colleagues' collaboration and attitudes towards research may affect the ongoing research process as well (McCown and Moss, 2002). In this study, it was found that although teacher research was not tangibly or intangibly rewarded within school, participating teachers did find motivation by participating in inter-school sharing where they could share their knowledge gained from their classroom research.

\section{The Future of Teacher-Researchers}

Some key factors that promote high-quality teacher research have been identified by Campbell (2003). These factors included:

- autonomy and control of research questions and project design by the teacher researchers;

- a high quality of support for research projects, robust processes of self-monitoring, critical reflection and evaluation;

- transparent procedures for the dissemination and promoting debate of research projects and findings;

- the establishment of critical communities in which teachers' research is made public. (p. 383) 
Because of the emphasis on critical reflection, analysis and external authorization in research, teachers choose to conduct research instead of adopting other approaches such as curriculum development to examine their practice or address teaching and learning issues (Watkins, 2006). Overall, the essential role that teacher-researchers play in developing the knowledge base of teaching and learning should be acknowledged; both practitioners and academics have to develop a better understanding of how each party interprets and conceptualizes educational research (Watkins, 2006). The present study revealed that the university could be a vehicle that fosters inter-school exchange of knowledge. A knowledge-sharing community provides teacherresearchers from various schools a platform to share their experience and knowledge gained from their research process, and therefore, fosters their professional development. As such, interested teachers will be attracted to the teacher-researcher community under the guidance of academics from the universities. With appropriate training, motivation, as well as internal and external support, teachers should be able to carry out meaningful research in their classrooms (Watkins, 2006).

The following framework (see Figure 2) summarizes the push-and-pull factors of teacher research generated from the findings of this project and the discussion. Left-pointing arrows represent the pull factors, mainly derived from the school (teaching) context that hinder the existence of teacher research. The right-pointing arrows list the push factors, mainly contributed by the research supports from the university coupled with the collaborative efforts within school context that encourage teachers to carry out classroom research. The solid and dotted lines of the arrows represent the strength of the pushing or pulling effects on individual teachers. Solid lines indicate a stronger influence while dotted lines stand for a weaker one. The thinking bubble states the beneficial outcomes of teacher research when it is carried out successfully.

Figure 2. The Push-and-Pull Factors of Teacher Research.

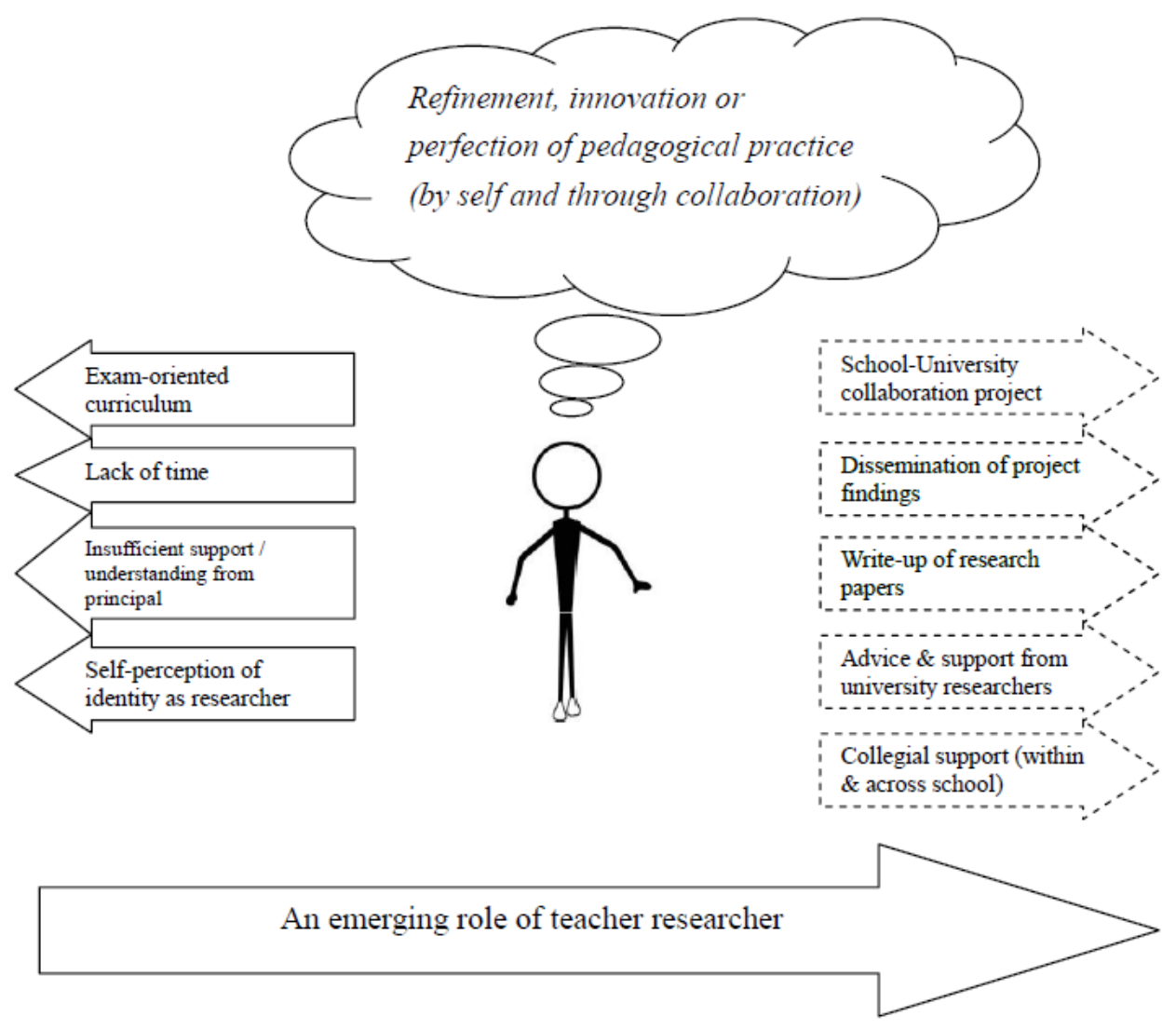




\section{Conclusion}

It was evident that teachers who participated in this school-university partnership project to promote inquiry $\mathrm{PjBL}$ were growing in their professional knowledge and skills, reporting stronger collaboration with colleagues to make their teaching more effective, revising their curriculum in response to students' needs, developing a more open-minded attitude towards research and experiencing an innovative school culture that is conducive to teacher-research. All these are believed to enhance teacher professionalism and teaching competency.

The reasons for the lack of a teacher-as-researcher culture in Hong Kong can be attributed to macro and micro factors. Macro factors include the conventional role and duties of teachers, which do not involve research, and teachers' perceptions of "research" as something complex that only academics at universities can do. Micro factors such as the limited focus on research skills in professional teacher training and time constraints caused by the tension from tight curriculum schedule further deter teachers from engaging themselves in research. The widely agreed local examination-oriented education system adds to teachers' burden, rendering time and effort devoted to examination preparation instead of other initiatives like classroom research.

Both internal and external support is arguably viewed as the key for teacher-research. School principals play an integral role in cultivating a school climate that engenders colleagues' collaboration, encouraging and enabling more flexible modification of teaching approaches and pedagogies to meet students' needs. A collaborative model is one where, on top of university support, teachers need to be well-prepared to take on the dual roles of teacher-practitioners and teacher-researchers. Amid the challenges of ongoing education reforms in Hong Kong and in all parts of the world, it is envisaged that the development of the role of the teacher as practitionerresearcher may have the potential of enhancing teachers' professionalism and competency in advocating positive changes alongside the reforms. In addition, close collaborations between university researchers and frontline teachers would bring positive impacts on the credibility of education research by providing empirical evidence and practical insights arisen from actual classrooms. 


\section{References}

Aaron, J., Bouchereau B. E., Commeyras, M., Dowling C. S., Daniell, B., Elrick, E., Vaughn, H. (2006). No deposit, no return: Enriching literacy teaching and learning through critical inquiry pedagogy. Newark: International Reading Association.

Atay, D. (2008). Teacher research for professional development. : English Language Teachers Journal, 62(2), 139-147. doi: 10.1093/elt/cc1053

Berger, J. G., Boles, K. C., \& Troen, V. (2005). Teacher research and school change: Paradoxes, problems, and possibilities. Teaching and teacher education: An International Journal of Research and Studies, 21(1), 93-105.

Biggs, J. (1994). Student learning research and theory: Where do we currently stand? Improving student learning: Theory and practice, 1-19.

Bissex, G. L. E., \& Bullock, R. H. E. (1987). Seeing for ourselves: Case-study research by teachers of writing. Portsmouth: Heinemann Educational Books.

Bray, J. N. (2000). Collaborative inquiry in practice: Action, reflection, and meaning making. Thousand Oaks: Sage Publications.

Bullough, R. V., \& Pinnegar, S. (2001). Guidelines for quality in autobiographical forms of selfstudy research. Educational Researcher, 30(3), 13-21.

Campbell, A. (2003). Teachers' research and professional development in England: Some questions, issues and concerns. Journal of In-Service Education, 29(3), 375-389.

Christenson, M., Slutsky, R., Bendau, S., Covert, J., Dyer, J., Risko, G., \& Johnston, M. (2002). The rocky road of teachers becoming action researchers. Teaching and Teacher Education, $18(3), 259-272$.

Clausen, K.W., Aquino, A.M., Wideman, R. (2009). Briding the real and ideal: A comparison between learning community characteristics and a school-based case study. Teaching and Teacher Education, 25(3), 444-452.

Cochran-Smith, M., \& Lytle, S. L. (1993). Inside/outside: Teacher research and knowledge. New York; London: Teachers College Press.

Cochran-Smith, M., \& Lytle, S. L. (1999). The teacher research movement: A decade later. Educational Researcher, 28(7), 15-25. doi: 10.3102/0013189x028007015

Croasdaile, S. (2007). What Makes Teachers Reflect to Improve Their Practice? Reflective Practice in a Social-Organizational Context: Online Submission. Retrieved from http://eric.ed.gov/?id=ED505866

Democratic Alliance for Betterment of Hong Kong (DAB). (2002). Hong Kong teacher stress survey. $\quad$ Retrieved June $8, \quad 2010, \quad$ from http://www.dab.org.hk/UserFiles/Image/News\%20centre/News/doc/2002/20021006poll. Pdf (in Chinese).

EDB. (2002). General studies for primary schools curriculum guide. Hong Kong SAR: Retrieved from http://cd.edb.gov.hk/kla_guide/GS_HTML/english/ch4/ch42.html. 
EDB. (2008). Teacher Training \& Qualifications. Hong Kong SAR: Retrieved from http://www.edb.gov.hk/en/teacher/qualification-training-development/qualification/teachertraining-qualifications/index.html

Elliott, J. (1991). Action research for educational change. Milton Keynes England: Open University Press.

Frost, D., MacBeath, J., O’Donovan, K., Sapsed, R. and Swaffield, S. (2013). Sustaining Teachers' Professional Growth, $18^{\text {th }}-19^{\text {th }}$ February 2013: A Report. Leadership for learning: the Cambridge Network: University of Cambridge.

Fullan, M. (2013). Stratosphere: Integrating technology, pedagogy, and change knowledge. Toronto, Canada: Pearson Canada.

Furlong, J., \& Salisbury, J. (2005). Best practice research scholarships: an evaluation. Research Papers in Education, 20(1), 45-83. doi: 10.1080/0267152052000341336

Goswami, D. E., \& Stillman, P. R. E. (1987). Reclaiming the classroom: Teacher research as an agency for change. Upper Montclair: Boynton/Cook Publishers.

Hargreaves, D. H. (1998). The knowledge-creating school. British Journal of Educational Studies, 47(2), 122.

Hoyle, E. (1980). Professionalization and deprofessionalization in education. World Yearbook of Education Professional Development of Teachers. Londres.

Kincheloe, J. L. (2003). Teachers as researchers qualitative inquiry as a path to mmpowerment.UK: Routledge.

Lam, Y. L. J. (1983). Building school capacity for effective teacher empowerment: application to elementary schools with at-risk students. In R. Ogawa (Ed.), Advances in research and theories of school management and educational policy. Newbury Park: Corwin.

Loughran, J. J. (2002). Teacher as researcher: The PAVOT project. In J. J. Loughran, I. J. Mitchell \& J. Mitchell (Eds.), Learning from teacher research. New York: Teachers College Press.

Louis, K. S., \& Kruse, S. D. (1995).Professionalism and community: Perspectives on reforming urban schools. Newbury Park: Corwin Press.

Louis, K. S., Marks, H. M., \& Kruse, S. (1996). Teachers' professional community in restructuring schools. American Educational Research Journal, 33(4), 757-798. doi: $10.3102 / 00028312033004757$

MacGilchrist, B., Reed, J., \& Myers, K. (2004). The intelligent school. Sage.

MacGilchrist, B., Mortimore, P., Savage, J., \& Beresford, C. (1995). Planning matters: The impact of development planning in primary schools. London: Chapman.

MacLean, M. S., \& Mohr, M. M. (1999). Teacher-researchers at work. Berkeley: National Writing Project, University of California.

McCown, R., \& Moss, C. M. (2002). The value of and the obstacles to becoming a teacher researcher: Practicing teachers' understandings of action research. Paper presented at the Annual Meeting of the American Educational Research Association, New Orleans. 
McDonald, F. J., \& Elias, P. (1983).The transition into teaching: The problems of beginning teachers and programs to solve them. Summary report. Princeton: Educational Testing Services.

Mohammad, R. F., \& Harlech-Jones, B. (2008). Working as partners for classroom reform. International Journal of Educational Development, 28(?), 534 - 545.

Morrow, P. C., \& Goetz, J. F. (1988).Professionalism as a form of work commitment. Journal of Vocational Behavior, 32(1), 92-111. doi: 10.1016/0001-8791(88)90008-5

Mourshed, M., Chijioke, C., \& Barber, M. (2010). How the World's Most Improved School Systems Keep Getting Better, a report McKinsey \& Company. McKinsey \& Company http://www.mckinsey.com/clientservice/Social_Sector/our_practices/Education/Knowledge _Highlights/How\% 20School, 20.

Myers, M. (1985). The teacher-researcher: How to study writing in the classroom. Urbana: National Council of Teachers of English.

Rathgen, E. (2006).In the voice of teachers: The promise and challenge of participating in classroom-based research for teachers' professional learning. Teaching and Teacher Education, 22, 580-591.

Roulston, K., Legette, R., Deloach, M., \& Pitman, C. B. (2005). What Is "Research" for TeacherResearchers? Educational Action Research, 13(2), 169-190.

Rust, F.O. (2009).Teacher research and the problem of practice. Teachers College Record, $111(8), 1882-1893$.

Sellars, M. (2012). Teachers and change: The role of reflective practice. Social and Behavioral Sciences, 55(?), $461-469$.

Shakir-Costa, K., \& Haddad, L. (2009). Practitioner research success! Science and Children, 46(5), 25-27.

Toh, K.-A., Diong, C.-H., Boo, H.-K., \& Chia, S.-K. (1996). Determinants of teacher professionalism. Professional Development in Education, 22(2), 231 - 244.

Tschannen-Moran, M. (2009).Fostering teacher professionalism in schools: The role of leadership orientation and trust. Educational Administration Quarterly, 45(2), 217-247.

Watkins, A. (2006). So what exactly do teacher-researchers think about doing research? Support for Learning, 21(1), 12-18.

Zeichner, K. M. (1993). Action research: Personal renewal and social reconstruction. Educational Action Research, 1(2), 199-219.

Zeichner, K. M., \& Noffke, S. E. (2001).Practitioner research. In V. Richardson (Ed.), Handbook of research on teaching (4th ed., pp. 293-330). Washington, D.C.: American Educational Research Association. 
Appendix 1. A list of publications with participating teachers' involvement.

1) Fu, O.H., Chu, S.K.W. \& Kang, W.X. (2011). The affordances of wiki for primary-school students' group project work. Paper presented at the International Conference on Addressing Student Learning Diversity in Hong Kong, Hong Kong.

2) Chow, K., Chu, S.K.W., Leung, O. \& Yu, S. (2011). Teachers as Researchers and the Development of Teacher Professionalism. Paper presented at CITE Research Symposium 2011, The University of Hong Kong, Hong Kong.

3) Law, H.C., Chu, S.K.W., Siu, F., Pun, B. \& Lei, H. (2011). Challenges of Using Google Sites in Education and How Students Perceive Using It. Paper presented at CITE Research Symposium 2011, The University of Hong Kong, Hong Kong.

4) 余澤濤、方志新、郭惠娟、羅詩敏、朱啟華、葉珈甄(2011)。研究匯報：利用Google Sites在常識科進行協作式專題研習。 優質教育基金研究計劃研討會。香港：香港大學教育應用資訊科技發展研究中心。 (English: Yu, C.T., Fong, C. S., Kwok, W. K., Law, S. M., Chu, S.K.W. \& Ip, I. (2011). Using Google Sites for Collaborative Inquiry Projects in General Studies. Paper presented at CITE Research Symposium 2011, The University of Hong Kong, Hong Kong.)

5) Chow, K., Chu, S. K. W., Tavares, N., Siu, F., Chu, D., Ho, S. Y. (2010). An emerging role of teacher-researchers in Hong Kong through a school-university collaborative research project. Forthcoming at The $2^{\text {nd }}$ East Asian International Conference on Teacher Education Research. The Hong Kong Institute of Education, Hong Kong. December 15-17, 2010.

6) Chu, D., Chu, S. K. W., Tavares, N., Siu, F., Chow, K. \& Ho, S. Y. (2010). Media awareness in the age of new media: A case study of Primary 4 students in Hong Kong. Paper presented at ASIS\&T 2010 Annual Meeting. Pittsburgh, PA, October 22-27, 2010.

7) 羅詩敏、朱啟華、鍾秀婷、許文俊、郭惠娟、張惠卿、余澤濤 (2010)。研究匯報：透過探究式學習改善小四學生的中文讀寫能力。 優質教育基金研究計劃研討會。香港：香港大學教育應用資訊科技發展研究中心

8）謝錦玉、朱啟華、胡詠恒、潘樂輝、袁樂肜、嚴儲文 (2010)。長洲聖心學校協作探究式專題研習(inquiry $\mathrm{PjBL})$ 的進程分享。優質教育基金研究計劃研討會。香港：香港大學教育應用資訊科 技發展研究中心

9) Fong, C.S., Chu, S.K.W., Tsang, G.W.K. \& Mak, M.Y.K. (2010). How Web 2.0 enhances 
collaborative teaching: the experience of Canossa Primary School. Paper presented at the Quality Education Fund Project Seminar: Sharing the Experience, The University of Hong Kong, Hong Kong, October 9, 2010.

10) Hui, O. S., Chu, K. W., Mak, Y. K., Yim, C., Pun L. F. \& Liu, T. (2010). The roles of teacher librarians in collaborative inquiry project-based learning. Paper presented at the Quality Education Fund Project Seminar: Sharing the Experience, The University of Hong Kong, Hong Kong, October 9, 2010.

11) Law, H. C., Chu, S.K.W., Pun, L. F. \& Huey, L. (2010). The role of Information Technology in collaborative inquiry project-based learning. Paper presented at the Quality Education Fund Project Seminar: Sharing the Experience, The University of Hong Kong, Hong Kong, October 9, 2010.

12) Chu, S. K. W., Chow, K., Wong, K. \& Ng, J. (2011). Inquiry project-based learning with Wiki at Primary 5 level with a collaborative teaching approach. Paper presented at $Q E F$ Project Dissemination Symposia: Applying a collaborative teaching approach to inquiry project-based learning with Web 2.0 at upper primary levels, the University of Hong Kong, Hong Kong, June 30, 2011. 